\title{
Civil Returns of Military Training: A Study of Young Men in Sweden ${ }^{\#}$
}

\author{
Niklas Hanes*, Erik Norlin, and Magnus Sjöström \\ Department of Economics, Umeå University, SE-901 87 Umeå Sweden
}

November 25, 2008

\begin{abstract}
The purpose of this paper is to study the effect of military training on earnings for young men in Sweden. The analysis is based on the cohort of men born in 1973. The 1973 cohort was conscripted during a time of rapid change in the Swedish security policy and substantial cutdowns of the armed forces. As a consequence, a relatively large part of the cohort was assigned a service category after the enlistment test but one third of these individuals were never conscripted. We argue that these organizational changes along with the set of important background variables that are available makes it possible to rely on selection on observables. A strong result is that military training has a positive effect on annual earnings at the age of 30 for the group in the private category that subsequently do not obtain an high educational level.
\end{abstract}

Key words: Earnings, Conscription, Enlistment test, Military training

JEL code: J01, J30, H56

\footnotetext{
${ }^{*}$ Corresponding author. Umeå University, Department of Economics, SE-901 87 Umeå, Sweden. Tel.:+46 90786 9586; fax +4670772203.

Email addresses: niklas.hanes@econ.umu.se, erik.norlin@econ.umu.se, magnus.sjostrom@econ.umu.se

\# The authors would like to thank Thomas Aronsson, Anders Stenberg, Roger Axelsson, and seminar participants at the Department of Economics, Umeå University, for valuable comments. This research was supported by the Swedish Council for Working Life and Social Research.
} 


\section{Introduction}

The armed forces are often referred to as a good place to start off since military training and experience may foster or signal personal traits such as leadership ability and perseverance. However, the effect of military experience on labor market outcomes is ambiguous. Second World War veterans have been found to experience positive wage premiums compared to non-veterans while the wage premium for Vietnam veterans have been negative (see, e.g. Rosen and Taubman, 1982, and Berger and Hirsch, 1983). One explanation that has been put forth is that the different returns to military experience are due to war specific circumstances, e.g. the public opinion, or differences in the skills and experiences that are obtained during service. More resent research has found that differences in subsequent labor market outcomes to a large extent can be explained by the selection process into the armed forces. For example, by utilizing the fact that the U.S. recruitment in the conscription system during World War II was based on the date of birth, Angrist (1998) shows that veterans from World War II did not earn more that non-veterans.

The purpose of this paper is to analyze to what extent Swedish military training is rewarded on the labor market. Sweden has a conscription system meaning that all men in Sweden are obliged to attend a military enlistment test and in the end military training. ${ }^{1}$ The study differs from many of the earlier studies as it concerns military training in peacetime and not military experience from war or international peacekeeping missions. Earlier literature has shown that the selection problem is crucial to handle in order to identify the effect of military training. The research strategy in this paper for identifying the training effect is built on two foundations. Firstly, in the post-cold war era the Swedish defense transformed from an invasion defense that required a large part of every cohort to be conscripted, to a relatively small and highly technological organization with the main aim to participate in international peacekeeping missions. During the re-formation of the military defense a large number of individuals were assigned a service category after the enlistment test but were not conscripted due to extensive cut-downs and regiment closures. In our sample, that is restricted to Swedish men born in 1973 having Swedish born parents, approximately 35,000 individuals were

\footnotetext{
${ }^{1}$ Since 2007 all men are not called for enlistment test. A first web-based assessment is used to select individuals for the enlistment test. The reason for not calling the entire cohort for the test is mainly because a small share of the cohort is nowadays conscripted and the costs for testing the entire cohort cannot be motivated.
} 
assigned a service category. However, only 24,000 were finally conscripted, meaning that we have a control group of 11,000 individuals.

Secondly, the empirical analysis is based on a wide range of individual characteristics that can be linked to individual earning statistics. Although our control group is not selected on individual characteristics at the time of the enlistment test, the rich data set is important since a selection problem may arise in the process of regiment closedowns. During the transformation to a more highly technological defense requiring fewer conscripts, less advanced units were more likely to face cut-downs at the same time as these units may have required conscripts with lower "skill profile". Since we have access to the same information concerning individual characteristics as the National Service Administration, relying on selection on observables should be enough to identify the training effect (see Heckman and Robb, 1985, for a discussion). The data set contains a wide range of individual characteristics, e.g. parental characteristics, education levels, and test scores, all of which can be linked to individual earnings statistics. We also control for how well the individuals performed during military training since we have access to the grades given after military training.

Regression is our main approach but we also conduct matching to check the robustness of the regression results. In the empirical analysis we have constructed three subsamples with respect to the level of command, which are strongly correlated with the length of the training period. The private category has the shortest training period of approximately seven months. The squad leader category does ten months of training and the platoon leader category 15 months.

The paper contributes to the literature for (at least) two reasons. First, it focuses solely on training and not military experience during wartime or international peacekeeping missions. Second, the paper takes advantage of the transformation of the armed forces in the post cold war era. Furthermore, the results are of importance for the present debate concerning the military personnel recruitment in Sweden. The compulsive part of the Swedish conscription system has been strongly criticized in the post cold war era. Although it is in the interest of the armed forces that the conscripted men are motivated for the task, the compulsory element of the conscription system is evident since young men that refuse to be conscripted can still be sentenced to imprisonment. In this context, it is of interest to have knowledge of the impact that military service has on the individuals' labor market outcomes.

The main result is that military training has a positive effect on earnings for the private category. Furthermore, the positive effect is dependent upon the educational level; 
individuals with low education benefit the most from participating in military training. ${ }^{2}$ When applying regression analysis, some evidence is also found of a positive earnings effect for the squad leaders that subsequently do not obtain high education. However, this effect is not present when matching is conducted. We do not find any evidence that military training has an impact on earnings for individuals drafted for the platoon leader category.

The rest of the paper is organized as follows. In the next section, a review of earlier comparable literature is presented. In section 3, we discuss our research strategy and data, and also compare the control group with the conscripted in different dimensions. Section 4 contains the empirical model. The results are presented in section 5, and section 6 concludes.

\section{Earlier literature}

There is an extensive literature dealing with the impact that military training and experience have on individuals' earnings and employment. Most studies are based on U.S. data but they do not give a unanimous picture of the effect of military training and experience on labor market outcomes. From an economic perspective the civilian return of military service can be analyzed within two traditional frameworks of labor economics: the human capital hypothesis and the screening hypothesis. According to the former, civilian return of military service is a result of the transferability of skills between military service and the civilian sector. The screening hypothesis, on the other hand, highlights that even if the military service does not improve any skills useable in the civilian sector, the service as such provides information about personal characteristics that will affect the post service civilian earning and employment positively or negatively. From an empirical point of view it is of course difficult to separate these effects.

A number of studies find that veterans from World War II experienced positive wage premiums compared to non-veterans, while Vietnam veterans were not rewarded for their military experience (see e.g. Rosen and Taubman, 1982, and Berger and Hirsch, 1983). Several possible explanations concerning this pattern have been discussed. For example, the different returns for veterans have been attributed to the public opinion, which may explain

\footnotetext{
${ }^{2}$ A possible objection to our analysis is that it may be too early to study earnings at the age of 30 , at least for individuals with higher education. Different results, with respect to the individuals' education level, may be found if the study is repeated later on, studying earnings in later years.
} 
the favorable situation for World War II veterans compared to Vietnam veterans. Another explanation is that the skills that veterans have acquired during services can differ between time periods. Several studies have also found that the returns of military experience depend on the arm of the service (see, e.g. Goldberg and Warner, 1987). Bryant and Wilhite (1990) find evidence that military training has a positive effect on wages, while the length of the military career affects wages in the civil life negatively.

A general methodological problem that is present in many studies is the selection process into the armed forces. Firstly, a conscription system implies a screening process where the most suitable men are chosen for a specific service. Secondly, voluntary enrolment implies that individuals are self-selected into the armed forces. In both cases, it is likely that unobserved heterogeneity leads to comparisons that may be befouled with selection bias. The antecedent empirical studies typically disregarded the selection problem; later studies have in line with the return-to-schooling literature tried to the handle selection bias. The development of methods for handling self-selection has also contributed with new insights regarding the impact of military experience on labor market outcomes.

As noted, several studies find positive effects of military experience in OLS regressions for Second World War veterans in contrast to the negative effects found for Vietnam veterans. Angrist and Krueger (2001) present estimates based on instrumental variables for World War II veterans. The instruments are constructed by using the fact that conscription was determined by the date of birth. The results presented by Angrist and Krueger indicate that World War II veterans do not earn more than non-veterans and they may also earn less. Angrist (1990) uses a draft lottery during the Vietnam War in order to obtain non-biased estimates of the effect of military services. The results presented by Angrist indicated that earnings of white veterans in the early 1980's were 15 percent less than earnings of non-veterans. For non-white veterans, no significant results were found. Angrist argue that the negative effect of military services can be explained by less civilian job experience. A later study by Angrist (1998) analyses employment rates and earning for U.S. veterans who served in the early 1980's. In this study Angrist applied two strategies for dealing with selection. Firstly, he compared enlisted with those applicants who did not enlist. The second strategy was to use an instrumental variable method based on an error in the scoring of exams during screening. Angrist found that employment rates after military services were higher for veterans. The increase in civilian earning was small for nonwhites and white veterans experienced a negative effect of military services on earnings. 


\section{Research strategy and data}

The empirical analysis in this study is based on the cohort of men born in 1973 and residing in Sweden on December 31, 1990. Data have been obtained from Statistics Sweden (SCB), and The National Service Administration (Pliktverket). The total sample contains 57,709 men, 46,305 (80.2 percent) of these are born in Sweden with Swedish born parents, 4,095 are foreign-born (7.1 percent), and 7,309 are second-generation immigrants (12.7 percent). In this paper we have excluded the foreign born individuals and second-generation immigrants in order to avoid discrimination issues.

\subsection{The enrolment process}

The first paragraph of the Swedish Act on Liability for Total Defense Service states "The Total Defense is a concern for all inhabitants (of Sweden)". This means that the personnel needed by the total defense are secured by a liability for every Swedish citizen aged between 16 and 70. As stated in the act, this obligation is also valid for all individuals living in Sweden without Swedish citizenship. Services within the total defense can be military, civil, or general. According the act, all military and civil services contain some basic training, refresher training, readiness service and wartime service. However, only men with Swedish citizenship are obliged to do military training.

According to the Swedish Act on Liability for Total Defense Service, all males with Swedish citizenship have to attend the enlistment test at the Swedish National Service Administration. Generally, the individuals are called for at the age of 18 . The enlistment test takes two days to carry out and comprises physical tests ${ }^{3}$, cognitive tests ${ }^{4}$, an evaluation of psychological ability ${ }^{5}$, and a test of leadership ability. The individual is ranked from 1-9 in all categories ( 1 is low ability and 9 is high ability). The testing procedure aims at estimating the individuals' ability to fulfill military services and to choose the suitable individuals for different services.

\footnotetext{
${ }^{3}$ The physical tests comprise aerobic test, muscle strength, length and weight.

${ }^{4}$ The cognitive test is made up by four different sub-sections; instructions, synonyms, technical comprehension, and metal folding. The test scores are summed and transformed into the nine-point scale.

${ }^{5}$ The psychological ability test score is based on an interview conducted by a psychologist during the military enlistment test. The main purpose of the test is to identify the individual's social skills, emotional stability, and ability to handle stress.
} 
The range of service categories within the armed forces is numerous. Services such as infantry soldiers in many different categories, paratroopers, engineers, cryptographers, interpreters, and nurses are just a few examples that highlight the wide spectrum of services. The military training period range from 60 to at most 615 days (see the Swedish Act on Liability for Total Defense Services). For the period we study, the most common services have training periods of 7,10 , and 15 months. The length of the period is often associated with the level of command for wartime service. The shortest training period of up to seven months is for the private ${ }^{6}$ category, ten months of training periods are generally observed for squad leaders, and platoon leaders have the longest training period of 15 months. There are however variation in training periods, especially for some specialist categories such as paratroopers where all enlisted have training periods of 15 months.

\subsection{Data and control groups}

Due to the change in the Swedish security policy and the cut downs of the armed forces, a relatively large share of the cohort was assigned a service category but was never conscripted, i.e. these individuals did not start the military training. In Table 1, the number of men in the cohort (with two Swedish-born parents) is first presented. From this group, individuals were called for enlistment test. As can be seen from the table, approximately five percent of the cohort were not tested, mainly due to medical reasons. Of the individuals that were tested, approximately 80 percent was assigned a service category. Out of the approximately 35,000 men that were assigned a service category, only about 24,000 were conscripted. This means that we have a control group of approximately 11,000 men.

Table 1. The cohort of Swedish born having two Swedish-born parents divided and its selection into military service.

\begin{tabular}{lc}
\hline \hline Group & Number of individuals \\
\hline \hline Cohort & 46,305 \\
Called for enlistment test & 43,939 \\
Tested & 43,340 \\
Assigned a service category & 35,414 \\
Conscripted & 23,886 \\
\hline
\end{tabular}

Note: The cohort refers to the number of individuals with Swedish-born parents.

\footnotetext{
${ }^{6}$ The category private is in this paper also used for the air force (air man) and the navy (sea man).
} 
For our purposes it is important to compare the characteristics of the conscripted group with the control group (assigned a service but not conscripted). The groups are compared with respect to the psychological ability and cognitive ability that are evaluated at the enlistment test; these indicators are important determinants for the assignment of service category. ${ }^{7}$ For the squad leader and platoon leader categories we have also compared the evaluation of leadership ability. The leadership ability is evaluated if the individual scoring five or higher on the cognitive test. We have not presented the mean values of the leadership ability for the private category since a large share of the group has not been evaluated.

Since the cohort was conscripted during a time of extensive reformation of the armed forces, we argue that it is reasonable to consider the control group as randomized. If the consequences of the military cut-downs and closedowns of regiments were fully anticipated, we would expect the armed forces to have taken advantage of the option to choose the most suitable men for the military services. ${ }^{8}$ In this case we should observe substantial differences between the groups. ${ }^{9}$ As was mentioned earlier, a possible source of selection may be found in the process of regiment closedowns. Less advanced units may have

\footnotetext{
${ }^{7}$ We have also access to the grade point average (GPA) from the $9^{\text {th }}$ year of compulsory school. However, we do not consider the GPA in the analysis since it is highly correlated with the cognitive test score. If GPA is used in the empirical analysis instead of the cognitive test score, the main results are not altered.

${ }^{8}$ Although we have access to a wide range of individual characteristics, we cannot rule out that the military defence has access to information (individual characteristics) that is not available to us. Such unobserved characteristics (for the researcher) may origin from the individuals' preferences for military services. However, we cannot find any reasonable argument that strong preferences for the armed forces should be correlated with higher productivity in the civil life. For the platoon leader category, where the individual's assent is required, it is not reasonable to argue that the conscript group is more motivated than the control group. Preferences for the military defence may also affect some of the control variables. A person with an aversion to military training might try to underachieve during the tests. In this case, the true ability of the control group is actually higher and earnings effect of completing military training will be underestimated.

${ }^{9}$ For later cohorts, the group of conscripts is certainly not randomised since the military defence has adapted to the new security policy environment. One example of the adaptive process is the so-called education reserve that was implemented after the 1992 defence resolution. One implication of the reserve was that individuals were tested and afterwards placed in the reserve without an assignment of a service category. These individuals were seen as a possible source of future conscripts if new security policy threats would emerge. However, 98 percent of the 1973 cohort was tested prior to the implementation of the education reserve so the risk of selection bias stemming from this source seems remote.
} 
required conscripts with lower "skill profile", these units were more likely to face cut-downs. However, since we have the same information as the National Service Administration, relying on selection on observables should be enough.

Before examining the characteristics of the conscripts and the control group, an interesting question is how the characteristics of these two groups compares to the share of the cohort that have been tested but have not been assigned a service category. As can be seen from Table 1 this group consists of 7,926 individuals. Table 2 presents mean values of psychological ability and the cognitive test. It is clear that the individuals that have not been assigned a service category have on average lower values for both measures. The most noticeable difference is with respect to the psychological ability.

Table 2. Mean values for tested and service category assigned (conscripted and non-conscripted) and tested and no service category.

\begin{tabular}{lccc}
\hline \hline & $\begin{array}{c}\text { Service category } \\
\text { Conscripted }\end{array}$ & $\begin{array}{c}\text { Service category } \\
\text { Non-conscripted }\end{array}$ & No service category \\
\hline Psychological ability & 5.59 & 5.44 & 3.61 \\
Cognitive test & 5.35 & 5.24 & 4.32 \\
\hline
\end{tabular}

In Tables 3 through 8 descriptive statistics are presented for the private category, the squad leader category, and the platoon leader category. In Tables 3 and 4 descriptive statistics for the individuals with a private category assignment are presented; Table 3 contains the group that have not been conscripted and Table 4 the group that have been conscripted and completed their military training.

Table 3. Descriptive statistics, private category, non-conscripted.

\begin{tabular}{lccccc}
\hline Variable & Mean & Min & Max & Std dev & Observations \\
\hline \hline Psychological ability & 4.70 & 1 & 9 & 1.34 & 9,047 \\
Cognitive test & 4.52 & 1 & 9 & 1.71 & 9,349 \\
\hline
\end{tabular}

Table 4. Descriptive statistics, private category, conscripted.

\begin{tabular}{lccccc}
\hline Variable & Mean & Min & Max & Std dev & Observations \\
\hline \hline Psychological ability & 5.01 & 1 & 9 & 1.36 & 14,613 \\
Cognitive test & 4.70 & 1 & 9 & 1.74 & 14,999 \\
\hline
\end{tabular}


Some differences can be observed although they are relatively small. The evaluation of psychological ability and the score from the cognitive enlistment test is somewhat higher in the conscripted group. In Tables 5 and 6, descriptive statistics can be found for squad leaders. The group of squad leaders who has fulfilled their services is almost three times larger than the control group. As can be seen from the table, there are very small differences between the two groups. The test of cognitive skills is marginally higher in the control group.

Table 5. Descriptive statistics, squad leader, non-conscripted.

\begin{tabular}{lccccc}
\hline Variable & Mean & Min & Max & Std dev & Observations \\
\hline Psychological ability & 6.16 & 2 & 9 & 1.18 & 1,990 \\
Cognitive test & 6.47 & 3 & 9 & 1.27 & 1,991 \\
Leadership & 6.08 & 2 & 9 & 1.04 & 1,986 \\
\hline
\end{tabular}

Table 6. Descriptive statistics, squad leader, conscripted.

\begin{tabular}{lccccc}
\hline Variable & Mean & Min & Max & Std dev & Observations \\
\hline \hline Psychological ability & 6.38 & 3 & 9 & 1.11 & 5,742 \\
Cognitive test & 6.30 & 2 & 9 & 1.24 & 5,744 \\
Leadership & 6.18 & 3 & 9 & 1.00 & 5,728 \\
\hline
\end{tabular}

Turning to the platoon leader category (Tables 7 and 8) there are very small differences in characteristics between the groups. It is important to note that an individual cannot be conscripted as a platoon leader on a compulsory basis. The individual's assent is required for this service category.

Table 7. Descriptive statistics, platoon leader, non-conscripted.

\begin{tabular}{lccccc}
\hline Variable & Mean & Min & Max & Std dev & Observations \\
\hline \hline Psychological ability & 7.29 & 4 & 9 & 0.97 & 980 \\
Cognitive test & 7.33 & 5 & 9 & 1.12 & 980 \\
Leadership ability & 7.26 & 5 & 9 & 0.87 & 980 \\
\hline
\end{tabular}


Table 8. Descriptive statistics, platoon leader, conscripted.

\begin{tabular}{lccccc}
\hline Variable & Mean & Min & Max & Std dev & Observations \\
\hline \hline Psychological ability & 7.33 & 4 & 9 & 0.92 & 2,271 \\
Cognitive test & 7.18 & 5 & 9 & 1.14 & 2,271 \\
Leadership ability & 7.25 & 4 & 9 & 0.83 & 2,271 \\
\hline
\end{tabular}

To sum up this short review of the descriptive statistics there are no large differences between the groups and the strategy to rely on selection on observables seems plausible. Finally, a comparison that we have so far not mentioned is the difference in the outcome variable of the analysis. A first comparison that might be interesting is to look at the earnings for the share of the cohort that was assigned a service and the group that was called for the enlistment test but was not assigned a service category for different reasons. The average earnings in 2003 (at the age of 30) for the former group are SEK 249,455 and SEK 204,831 for the latter group. The average earnings in 2003 for the conscripted group as a whole are SEK 254,396, which can be compared with SEK 240,124 for the enrolled but non-conscripted group. It is evident that the armed forces are able to select individuals for military training that are also productive in the civil life. It is also clear that the group that has completed military training has higher earnings on average compared to the non-conscripted group.

\section{Empirical model}

\section{Regression approach}

The natural logarithm of earnings at the age of 30 is regressed on parental characteristics, schooling characteristics, ability characteristics measured during the enlistment test, variables describing the military training and other controls. The earning equation is estimated separately for the three samples, each sample representing a level of command (private, squad leader, platoon leader). The following earning equation is estimated by ordinary least squares,

$$
\ln y_{i}=\alpha_{i}+\beta P_{i}+\phi S_{i}+\gamma A_{i}+\lambda M_{i}+\theta Z_{i}+\varepsilon_{i}
$$

where $\ln y_{i}$ is the natural logarithm of earnings in 2003 for individual $i, \alpha_{\mathrm{i}}$ is a constant. $P_{i}$ is a vector of parental characteristics and $S_{i}$ is a vector of schooling variables. Individual characteristics measuring ability from the enlistment test are included in $A_{i}$. The vector $M_{i}$ 
contains variables describing the military training that individual $i$ have participated in and the grades from military training. The vector $Z_{i}$ contains a number of other control variables. $\beta, \phi, \gamma, \lambda$, and $\theta$ are vectors of parameters to be estimated and $\varepsilon_{i}$ is an error term.

Variable definitions are presented in Table 9 and descriptive statistics are presented in Table A1 in the appendix. The dependent variable consists of labor income in 2003 , i.e. when the individual is 30 years old. Individuals with annual earnings less than 40,000 SEK (approximately 4,300 EURO) are excluded. ${ }^{10}$ Individuals that obtained their highest education level in 2003 as well as individuals receiving study aid in 2003 are also excluded. Parental characteristics include the highest education of the father or mother and an average earnings variable measured as the mean earnings for the mother and father for the years where data is available (1990-1992). ${ }^{11}$

A dummy variable is included to control for the highest level of education that is obtained by the individual. Low education is defined as no more than upper secondary education and high education is defined as post upper secondary education. Experience measured as the number of years since the highest degree is also included as an explanatory variable. The squared experience is also included. Three additional controls are also included; marriage, local unemployment in 2003, and a set of dummy variables capturing the region of residence at the time of the enlistment test.

Three variables from the military enlistment test have been included in the regressions. The first is the test of the cognitive ability and the second is the evaluation of psychological ability. The final military enlistment test variable is the leadership ability that is only evaluated if the individual's score on the cognitive test is five or higher. The leadership ability is only available for the squad leader and platoon leader categories (and a small share of the private category). As a consequence the leadership variable is not included in the analysis of the private category.

We have previously discussed our research strategy for identification of the wage premium of military training. Military training is identified by a dummy variable that takes the value one if the individual has completed military training and zero otherwise. To only consider participation might give an unbalanced picture of the training. Military training is likely to foster or signal a wide range of personal traits that may be rewarded on the labor

\footnotetext{
${ }^{10}$ See Antelius and Björklund (2000) for a discussion of income restrictions. Alternative cut-off level of SEK 80,000 and SEK 100,000 have also been tested without altering the main results.

${ }^{11}$ The educational level and incomes of the adults living in the same household as the child during the years 1990-92 are available. Thus, an adult defined as a parent is not necessarily the child's biological parent.
} 
market, e.g. leadership ability, team working, and endurance. However, some of the military training requires personal traits that may not be productivity enhancing for all workers. An employer searching for low skilled labor may not see strong leadership ability as a favorable trait; a tendency to follow all instructions without questioning might be rewarded in the military services for private categories but may not be seen as a good personal characteristic by some employers looking for creative and self-driven workers. In the empirical analysis we add an interaction variable between military training and education level in order to control for different effects of military training. In addition we have also access to the grades given after completed training; i.e. a measure of how well the individual has performed during training. Three grades are given and consider, manners, qualification for the position, and knowledge and skills. An interaction variable is constructed that combines the dummy variable for military training with an average of the three grades.

\section{Matching approach ${ }^{12}$}

Both the regression technique and the matching approach rely on the conditional mean independence assumption. However, while regression analysis also rest on an additional assumption that conditioning linearly will remove the selection bias, matching solves the selection problem by either non-parametric or semi-parametric methods. An additional difference between the two methods is that when obtaining the regression estimates, no care is taken to ensure that comparable observations exist.

A probit model is estimated as a first step in the matching procedure. Based on the probit model, matching is carried out on the resulting propensity score. The probit model is fitted by including the following variables; a constant, a set of dummy variables capturing the region of residence when undergoing the military enlistment test, parental income, parental education, test score on the psychological ability evaluation, test score on the cognitive ability evaluation, and score on the leadership ability test (not included for the private category). Two different matching methods are used; nearest neighbor matching and kernel matching using kernel type Epanechnikov. Nearest neighbor matching is carried out with replacement using one respectively four neighbors. The Epanechnikov approach is implemented using a bandwidth of $0.01,0.05$ and 0.10 , respectively. The effect in focus in both the kernel and nearest neighbor strategy is the average treatment effect on the treated.

\footnotetext{
${ }^{12}$ For a detailed description of matching, see e.g. Heckman et al. (1998), Imbens (2004) and Smith and Todd (2005).
} 
Table 9: Variable definitions of dependent and independent variables used in the ordinary least squares regression, descriptive statistics are presented in the appendix.

\begin{tabular}{|c|c|}
\hline Variable & Definition \\
\hline $\ln y_{i}$ & Natural logarithm of annual earning for individual $i$ in 2003. \\
\hline FamInc $_{i}$ & $\begin{array}{l}\text { Parental income measured as the average earning of the mother and father for the years 1990- } \\
1992 .\end{array}$ \\
\hline FamEdu & $\begin{array}{l}\text { The highest education level obtained by the mother or the father (compulsory school, vocational } \\
\text { training, three years of upper secondary school, less than two years of post secondary schooling, } \\
\text { three years or more of post secondary schooling). }\end{array}$ \\
\hline Married $_{i}$ & Indicates that the individual is married in 2003. \\
\hline Unempl & Unemployment rate in the municipality where the individual is residing in 2003. \\
\hline County & $\begin{array}{l}\text { Dummy variable indicating the county where the individual is residing the year the enlistment } \\
\text { test is conducted. }\end{array}$ \\
\hline$L o w E d u_{i}$ & The variable indicates that three years of upper secondary school is the highest education level. \\
\hline HighEdu $u_{i}$ & The variable indicates that university education is the highest education level. \\
\hline Experience $_{i}$ & The number of years since the highest education was obtained. \\
\hline Experience $2_{i}$ & The squared number of years since the highest education was obtained. \\
\hline $\operatorname{Cog} n_{i}$ & $\begin{array}{l}\text { A variable ranking the individuals score on the cognitive test in the military enlistment test. The } \\
\text { measure range from } 1-9 \text { and } 5 \text { is the average value for the population. } 1 \text { is low ability and } 9 \text { is } \\
\text { high ability. }\end{array}$ \\
\hline PsAbility $_{i}$ & $\begin{array}{l}\text { A measure of psychological ability that is evaluated at the enlistment test by psychologists. The } \\
\text { measure range from } 1-9 \text { and } 5 \text { is the average value for the population. } 1 \text { is low ability and } 9 \text { is } \\
\text { high ability. }\end{array}$ \\
\hline Leader $_{i}$ & $\begin{array}{l}\text { A measure of leadership ability that is evaluated at the enlistment test by psychologists. The } \\
\text { measure range from } 1-9 \text { and } 5 \text { is the average value for the population. The evaluation is only } \\
\text { conducted if the individual receives a score above average on the cognitive test. } 1 \text { is low ability } \\
\text { and } 9 \text { is high ability. }\end{array}$ \\
\hline $\mathrm{Mil}_{i}$ & A variable taking the value one if the individual have done military services, zero otherwise. \\
\hline Mil_Gr $r_{i}$ & $\begin{array}{l}\text { An interaction variable between } M i l \text { and the average grade received after military service. The } \\
\text { average grade comprises three assessments: manners, qualification for the position, and } \\
\text { knowledge and skills. The assessment should not be compared for different positions or level of } \\
\text { commands, i.e. a grade 10-7-7 which is generally seen as a good grade, is not comparable } \\
\text { between a private category and squad leader. As a point if reference, the grade 10-7-7 is } \\
\text { required for service in international missions or admission to military academy. }\end{array}$ \\
\hline Mil_LowEdu & An interaction variable between completed military training and low education level \\
\hline Mil_HighEdu & An interaction variable between completed military training and high education level. \\
\hline
\end{tabular}

Note: The assessment of manners is generally expected to be graded ten. A grade lower than ten is observed in less than one percent for the present cohort, which might be seen as a negative signal on the labor market. In the empirical analysis we have also estimated models where a dummy variable is added for the cases where the grade for manners is lower than ten, however, no significant effect of the variable was found. 


\section{Results}

The ordinary least square estimates for all three categories are presented separately in Tables 10-12. Four different specifications are presented for each category. The first column displays results when all individuals in the category are included and no interaction term between completed training and educational level is used. In the second column, the interaction term between completed training and educational level is added; once again all individuals in the category are included. Columns three and four display the results when separate regressions are estimated on groups with different educational levels. Naturally, no interactions between completed training and educational level are added in these specifications.

The effects of parental variables are somewhat ambiguous. Firstly, average income for the mother and father seems to have a positive effect on earnings. Educational level among parents has a negative effect on earnings for the private and squad leader category, whereas no significant effects are found in the platoon leader category. One explanation to this general pattern in the parental variables is that education levels and earnings among parents are relatively strong correlated. When earnings are excluded the parameter for parental education is positive and significant, the main results are not sensitive to this alteration.

A robust result is that the score on the cognitive test has a positive effect on earnings. This result holds for all specifications, except for the small group having low educational level in the platoon leader category. The parameter for the psychological ability is significant and positive for the private category. For the squad leader category and platoon leader category we have also added the evaluation of leadership ability. The leadership ability and psychological ability are highly correlated and the leadership ability seems to large extent override the effect of psychological ability; for squad leaders, leadership ability has a positive and significant effect in all four regressions while three out of the four regressions in the platoon leader category show positive and significant effects. Significant and positive effects of psychological ability are still found in three out of four of the regressions for the squad leader category. All of the parameter estimates on psychological ability are insignificant in the platoon leader category.

The parameters for the dummy variable indicating educational level show the expected pattern, i.e. that individuals with higher educational level have higher earnings. The effect is significant in the private and squad leader categories but insignificant in the platoon 
leader category. The estimated parameter of the experience variable is positive and the parameter estimate of experience squared is negative. ${ }^{13}$

Table 10: OLS results for the private category.

\begin{tabular}{lcccc}
\hline Variable & All & All & Low Educ & High Educ \\
\hline \hline Constant & $7.307^{* * *}$ & $7.303^{* * *}$ & $7.202^{* * *}$ & $7.323^{* * *}$ \\
FamInc & $0.00004^{* * *}$ & $0.00004^{* * *}$ & $0.00005^{* * *}$ & $0.00002^{* * *}$ \\
FamEdu & $-0.012^{* * *}$ & $-0.012^{* * *}$ & $-0.014^{* * *}$ & $-0.010^{* *}$ \\
Cogn & $0.017^{* * *}$ & $0.018^{* * *}$ & $0.016^{* * *}$ & $0.022^{* * *}$ \\
PsAbility & $0.028^{* * *}$ & $0.029^{* * *}$ & $0.024^{* * *}$ & $0.040^{* * *}$ \\
HighEduc & $0.156^{* * *}$ & $0.182^{* * *}$ & & \\
Experience & $0.059^{* * *}$ & $0.058^{* * *}$ & $0.069^{* * *}$ & $0.120^{* * *}$ \\
Experience 2 & $-0.003^{* * *}$ & $-0.003^{* * *}$ & $-0.003^{* * *}$ & $-0.009^{* * *}$ \\
Mil & $0.023^{* * *}$ & $0.035^{* * *}$ & $0.037^{* * *}$ & -0.005 \\
Mil_HighEduc & & $-0.041^{* * *}$ & & \\
Adj R $R^{2}$ & 0.079 & 0.080 & 0.051 & 0.085 \\
F & 44.91 & 43.82 & 21.70 & 14.09 \\
Obs & 18,738 & 18,738 & 13,382 & 5,356 \\
\hline
\end{tabular}

Note: $* * *$ one percent significance level, ${ }^{* *}$ five percent significance level. Robust standard errors used to obtain t-values. Additional controls not displayed in the table are; a dummy variable capturing civil status (married/cohabiting or not), local unemployment in region of residence 2003, and a set of dummy variables capturing region of residence when undergoing the military enlistment test.

Turning to the results for the private category in Table 10, the dummy variable for military training has a positive and significant effect in column one. Thus, when all individuals in the category are included, regardless of educational level, an earnings effect of military training of approximately 2.3 percent is indicated. ${ }^{14}$ Adding the interaction between high educational level and completed military training, see column two, reveals that the positive effect stems from the low educational group. The effect of completing military training is 3.5 percent for the low educational group but 4.1 percent lower for the high

\footnotetext{
${ }^{13}$ In Tables A2-A4 in the appendix the sensitivity of the results to the conditioning on covariates that are determined after the military training is undertaken, i.e. experience, experience squared, educational level, marriage and local unemployment are excluded. This is particularly interesting for the low educational group. One reason for studying might be a weak labor market position. Thus, one might suspect that individuals obtaining their highest educational level (still defined as low) later to be negatively selected. Most of the main results are not altered.

${ }^{14}$ The calculation $\exp ($ coefficient)-1 transforms the coefficient to the exact percentage return.
} 
educational group. Both parameters are significant at the one percent level. Running separate regressions on each of the educational groups strengthens the conclusion that the earnings effect differ between the educational groups; column three indicates an earnings premium of 3.7 percent for individuals with low education and an insignificant loss of 0.5 percent for the high educational group.

Table 11: OLS results for the squad leader category.

\begin{tabular}{|c|c|c|c|c|}
\hline Variable & All & All & Low Educ & High Educ \\
\hline Constant & $7.187 * * *$ & $7.176 * * *$ & $6.736 * * *$ & $7.189 * * *$ \\
\hline FamInc & $0.00003 * * *$ & $0.00003 * * *$ & $0.00003 * * *$ & $0.00003 * * *$ \\
\hline FamEdu & $-0.013 * * *$ & $-0.013 * * *$ & $-0.009 *$ & $-0.016 * * *$ \\
\hline $\operatorname{Cog} n$ & $0.025 * * *$ & $0.025 * * *$ & $0.022 * *$ & $0.025 * * *$ \\
\hline PsAbility & $0.014 *$ & $0.014^{*}$ & 0.008 & $0.016^{*}$ \\
\hline Leader & $0.034 * * *$ & $0.034 * * *$ & $0.034 * * *$ & $0.035 * * *$ \\
\hline HighEduc & $0.130 * * *$ & $0.151 * * *$ & & \\
\hline Experience & $0.092 * * *$ & $0.092 * * *$ & $0.149 * * *$ & $0.138 * * *$ \\
\hline Experience ${ }^{\wedge} 2$ & $-0.006 * * *$ & $-0.006 * * *$ & $-0.007 * * *$ & $-0.010 * * *$ \\
\hline Mil & $0.020 *$ & $0.038^{*}$ & $0.043 * *$ & 0.014 \\
\hline Mil_HighEduc & & 0.028 & & \\
\hline $\operatorname{Adj} R^{2}$ & 0.091 & 0.091 & 0.050 & 0.093 \\
\hline$F$ & 18.02 & 17.52 & 3.27 & 10.72 \\
\hline Obs & 6,233 & 6,233 & 2,297 & 3,936 \\
\hline \multicolumn{5}{|c|}{$\begin{array}{l}\text { Note: } * * * \text { one percent significance level, }{ }^{* *} \text { five percent significance level, } * \text { ten percent } \\
\text { significance level. Robust standard errors used to obtain t-values. Additional controls not } \\
\text { displayed in the table are; a dummy variable capturing civil status (married/cohabiting or } \\
\text { not), local unemployment in region of residence } 2003 \text {, and a set of dummy variables }\end{array}$} \\
\hline
\end{tabular}

The squad leaders show a similar pattern as the private category. Column one in Table 11 shows that there is a 2.0 percent earnings effect for completing military training. The earnings effect is significant at the ten percent level. Column two indicates that the effect is larger for the low educational group, 3.8 percent, a parameter estimate significant at the five percent level. However, column two also shows that there are no significant difference in the earnings effect between the educational groups, although, the sign of the interaction indicates lower returns for individuals with more education. When separate regressions are run on each of the educational groups, the message concerning educational group differences in the earnings effect is stronger. Column three indicates that the earnings effect is 4.3 percent for 
the low educational group (significant at the 5 percent level), whereas no significant effect is found for the high educational group.

Table 12: OLS results for the platoon leader category.

\begin{tabular}{|c|c|c|c|c|}
\hline Variable & All & All & Low Educ & High Educ \\
\hline Constant & $7.239 * * *$ & $7.198 * * *$ & $5.718 * * *$ & $7.312 * * *$ \\
\hline FamInc & $0.00002 * * *$ & $0.00002 * * *$ & 0.00003 & $0.00002 * * *$ \\
\hline FamEdu & 0.002 & 0.001 & 0.004 & -0.001 \\
\hline $\operatorname{Cog} n$ & $0.019 * *$ & $0.019 * * *$ & 0.016 & $0.020 * *$ \\
\hline PsAbility & 0.008 & 0.007 & 0.051 & -0.002 \\
\hline Leader & $0.042 * * *$ & $0.042 * * *$ & 0.027 & $0.044 * * *$ \\
\hline HighEduc & 0.057 & 0.107 & & \\
\hline Experience & $0.118 * * *$ & $0.117 * * *$ & $0.273 * * *$ & $0.147 * * *$ \\
\hline Experience $^{\wedge} 2$ & $-0.009 * * *$ & $-0.009 * * *$ & $-0.013 * * *$ & $-0.012 * * *$ \\
\hline Mil & 0.010 & 0.068 & 0.072 & -0.005 \\
\hline Mil_HighEduc & & -0.069 & & \\
\hline $\operatorname{Adj} R^{2}$ & 0.104 & 0.104 & 0.128 & 0.098 \\
\hline$F$ & 8.61 & 8.31 & 2.75 & 6.41 \\
\hline Obs & 2,581 & 2,581 & 451 & 2,130 \\
\hline \multicolumn{5}{|c|}{$\begin{array}{l}\text { Note: } * * * \text { one percent significance level, } * * \text { five percent significance, } * \text { ten percent } \\
\text { significance level. Robust standard errors used to obtain t-values. Additional controls not } \\
\text { displayed in the table are; a dummy variable capturing civil status (married/cohabiting or } \\
\text { not), local unemployment in region of residence } 2003 \text {, and a set of dummy variables }\end{array}$} \\
\hline
\end{tabular}

Turning to the last category, platoon leaders, in Table 12, no significant earnings effects of military training are found. If only looking at the magnitude of the parameters the pattern is the same as before, i.e. the low educational group benefits from training, while the effect for the high educational group is around zero.

To sum up; the results indicate that there are positive earnings effects of serving in the private or squad leader category for individuals that subsequently do not obtain a high educational level. Thus, it seems as if some desirable skills are learned in the military, alternatively that having served signals desirable characteristics, and that these skills/characteristics are valued on the labor market. ${ }^{15}$

We have also run regressions when including the grade from military training. In Table 13 we display the results for the separate regressions on high and low educational

\footnotetext{
${ }^{15}$ We have also checked the robustness of all the OLS results to the timing of military service, i.e. during what year the training was undertaken. Neither the inclusion of a variable measuring the year of serving, nor exclusion of individuals that completed the military service later than 1994, changes the main results.
} 
groups in the three categories. It is clear that the performance during training matters, the estimate of the military grade is positive and significant in all sub groups. For the low (high) educational group in the private category, the cut-off point is a mean grade of 6.84 (8.21), e.g. the grade 10-5-5 (10-7-7) is an example of the highest grade below the cut-off point. Approximately 5 (53) percent of the individuals in the private category have an average grade that is below the cut-off point.

Table 13: OLS results including interaction between military training and educational level.

\begin{tabular}{|c|c|c|c|c|c|c|}
\hline \multirow[b]{2}{*}{ Variable } & \multicolumn{2}{|c|}{ Private } & \multicolumn{2}{|c|}{ Squad } & \multicolumn{2}{|c|}{ Platoon } \\
\hline & LowEduc & HighEduc & Low Educ & High Educ & Low Educ & High Educ \\
\hline Constant & $7.222 * * *$ & $7.338 * * *$ & $6.790 * * *$ & $7.209 * * *$ & $5.742 * * *$ & $7.321 * * *$ \\
\hline FamInc & $0.00004 * * *$ & $0.00002 * * *$ & $0.00003 * * *$ & $0.00003 * * *$ & 0.00003 & $0.00002 * * *$ \\
\hline$F a m E d u$ & $-0.014 * * *$ & $-0.009 * *$ & -0.009 & $-0.015 * * *$ & 0.004 & -0.001 \\
\hline $\operatorname{Cog} n$ & $0.017 * * *$ & $0.021 * * *$ & $0.021 * *$ & $0.025 * * *$ & 0.017 & $0.018 * *$ \\
\hline PsAbility & $0.023 * * *$ & $0.038 * * *$ & 0.008 & 0.014 & 0.056 & 0.002 \\
\hline Leader & & & $0.032 * *$ & $0.034 * * *$ & 0.020 & $0.043 * * *$ \\
\hline Experience & $0.068 * * *$ & $0.120 * * *$ & $0.143 * * *$ & $0.137 * * *$ & $0.273 * * *$ & $0.148 * * *$ \\
\hline Experience ${ }^{\wedge} 2$ & $-0.003 * * *$ & $-0.009 * * *$ & $-0.007 * * *$ & $-0.010 * * *$ & $-0.013 * * *$ & $-0.012 * * *$ \\
\hline Mil & $-0.216 * * *$ & $-0.340 * * *$ & $-0.230 * *$ & $-0.261 * * *$ & -0.264 & -0.227 \\
\hline Mil_Gr & $0.032 * * *$ & $0.041 * * *$ & $0.034 * * *$ & $0.034 * * *$ & $0.041 * *$ & $0.027 *$ \\
\hline $\operatorname{Adj} R^{2}$ & 0.053 & 0.088 & 0.052 & 0.096 & 0.133 & 0.100 \\
\hline$F$ & 21.81 & 14.21 & 3.44 & 10.74 & 2.91 & 6.42 \\
\hline Obs & 13,382 & 5,356 & 2,297 & 3,936 & 451 & 2,130 \\
\hline
\end{tabular}

Note: $* * *$ one percent significance level, $* *$ five percent significance level, * ten percent significance level.

Robust standard errors used to obtain t-values. Additional controls not displayed in the table are; a dummy variable capturing civil status (married/cohabiting or not), local unemployment in region of residence 2003, and a set of dummy variables capturing region of residence when undergoing the military enlistment test.

For the squad leader category, the cut-off point is 6.85 for the low educational group and 7.69 for the high educational group. In the low (high) educational group roughly 4 (21) percent of the individuals have an average grade that is below the cut-off point. Finally, the cut-off point in the platoon leader category is 6.44 (8.49) for the low (high) educational group. The fraction of individuals below the cut-off points is around 2 percent for the low educational group and 49 percent for the high educational group. A point of reference in this discussion is that the minimum requirement for recruitment to international peacekeeping missions is $10-7-7$. It is important to note that the grades are not comparable between the different groups since they reflect the skills and abilities for a specific service category. It is not clear how to interpret the effect of military grades. One possible interpretation is that the grade reflects the amount of human capital acquired during the military service, i.e. a human capital interpretation. 
Another, equally plausible, explanation is that individuals reveal their capacities during the training (beyond what is captured in the enlistment tests) and that these capacities are valued on the labor market. With the data at hand we cannot separate the two effects.

\subsection{Regression vs. Matching}

As mentioned above, the selection on observables strategy can be implemented either by regression or matching. In this subsection, the robustness of the regression results to the alternative approach will be studied. Table 14 reports the estimated earnings effect using regression (previously displayed in the first, third and fourth columns in Tables 10-12) and various matching procedures. The matching estimates reported are based on nearest neighbor matching with replacement (1 respectively 4 neighbors) and matching using kernel type Epanechnikov (bandwidth 0.01, 0.05 and 0.10). In all of the matching procedures a probit model was fitted to obtain the propensity score. Only a handful of the observations are off support in any of the sub groups when matching is carried out. The reported effect is the average treatment effect on the treated.

Table 14: Comparison of earnings effect obtained using regression and matching.

\begin{tabular}{lllllll}
\hline Group & OLS & NN(1) & NN(4) & Epan $(0.01)$ & Epan $(0.05)$ & Epan $(0.1)$ \\
\hline \hline PRIVATE & & & & & & \\
All & $0.023^{* * *}$ & $0.022^{* *}$ & $0.023^{* *}$ & 0.005 & 0.008 & 0.010 \\
Low Educ & $0.030^{* * *}$ & $0.042^{* * *}$ & $0.041^{* * *}$ & $0.032^{* *}$ & $0.033^{* *}$ & $0.033^{* *}$ \\
High Educ & -0.005 & -0.020 & -0.008 & -0.021 & -0.021 & -0.019 \\
SQUAD & & & & & \\
All & & & & & 0.003 & 0.003 \\
Low Educ & $0.020^{*}$ & 0.005 & 0.007 & 0.003 & 0.029 & 0.026 \\
High Educ & 0.014 & 0.040 & 0.037 & 0.024 & -0.006 & -0.006 \\
PLATOON & & -0.006 & -0.006 & -0.007 & & 0.013 \\
All & 0.010 & 0.038 & 0.019 & 0.001 & 0.015 & 0.092 \\
Low Educ & 0.075 & 0.071 & 0.068 & 0.091 & 0.086 & 0.000 \\
High Educ & -0.005 & 0.013 & 0.001 & 0.001 & 0.003 &
\end{tabular}

Note: $* * *$ one percent significance level, ** five percent significance level, * ten percent significance level. Robust standard errors are used to obtain the t-values in the regression. Additional controls used in the regression not displayed in the table are; a dummy variable capturing civil status (married/cohabiting or not), local unemployment in region of residence 2003, and a set of dummy variables capturing region of residence when undergoing the military enlistment test. 
According to Table 14, the results showing an earnings effect for individuals with low educational level serving in the private category remains. The positive and significant effect when all individuals in the private category are included, regardless of educational level, is prevalent when implementing a nearest neighbor strategy but not when the kernel approach is used. The most apparent difference between the regression and matching strategy in the private category is the estimated earnings effect for the high educational group; the estimate obtained in the regression is higher than all the matching estimates. In Table A2 in the appendix we can see that regressions using only the variables included in the matching approach show the same tendency as the matching estimates. The variables that seem to drive this are experience and experience squared. When using a regression approach and including only variables used in the matching, the positive earnings effect when all individuals are included regardless of educational level disappear. However, the positive and significant effect remains for the low educational group.

Turning to the results for the squad leader category, we see that no significant earnings effects are found in any of the groups (All, LowEduc or HighEduc). Again the most important difference, apart from the significance levels, is the high educational group. Just as for the private category, the estimate obtained for this group using regression is higher than all of the matching estimates. Reported in Table A3 in the appendix are results from regressions using only the variables included in the matching approach. Again, it is clear that the estimates for the high educational group is lower (and similar in magnitude to the matching estimates) if the full specification is used instead of leaving out covariates not included in the matching. For the low educational group the estimates using nearest neighbor matching is similar in magnitude (however insignificant) to the once obtained from regression, while the kernel approach result in somewhat smaller estimates.

Finally, no significant results are found for the platoon leader category using the matching strategy, results displayed in Table 14. If looking at the magnitudes of the estimates, the pattern from the regression analysis is repeated. Results when not including other variables than used in the matching procedure are displayed in Table A4 in the appendix.

To summarise, the conclusion that there is an earnings effect for individuals serving in the private category and subsequently not obtain a high educational level is strengthened by the results obtained using matching. No other significant earnings effects are found when implementing the selection on observables strategy. 


\section{Conclusions}

The purpose of this paper is to study the impact of military training on annual earnings for men at the age of 30. The analysis is based on the cohort of men born in 1973 and residing in Sweden on December 31, 1990. In order to avoid discrimination issues we only consider men with Swedish born parents.

The 1973 cohort was enlisted during a period when the armed forces experienced considerable cut-downs. As a consequence a relatively large share of the cohort was assigned a service category but was not conscripted. We argue that the change in the Swedish security policy offers an exogenous shift that can be used for identification of the training effect. Moreover, given that we have access to test results from the enlistment test as well as other important background variables we feel confident that relying on a selection on observables strategy is reasonable. Regression is our main approach but we also check the sensitivity of our results by implementing a matching strategy.

The empirical analysis is based on three sub-samples, representing different levels of command and different length of the training period (private, squad leader, platoon leader). Separate analyses are also carried out on groups of individuals with different educational levels. The regression results indicate that military training has a positive effect on earnings at the age of 30 for individuals serving in the private category and not subsequently obtaining higher education. This result is repeated when implementing a matching strategy. There may be several explanations to this result. One is that military training enhances skills and abilities that are rewarded only for some positions on the labor market, e.g. the tendency to follow instructions and orders may be highly rewarded in some sectors. Another explanation is that military training can be seen as a marginal post-secondary education, and the effect of this training is overridden by university education. When relying on regression analysis, a positive and significant effect on the group serving as squad leaders is also found. However, the significance of this result disappears when the matching strategy is applied. No significant earnings effects are found for the platoon leader category. In none of the three categories significant effects are found for the group of individuals that subsequently obtain a high educational level. The main results stemming from the regression approach are not altered if only including variables that are determined before undertaking the military training (i.e. if measures of experience, civil status and regional unemployment are excluded). The average grade received after completed training is positively associated with earnings. This result holds for all levels of command and all educational groups. 
Several questions are interesting for future research. The present analysis indicates that military training may have an effect on annual earnings for low educational groups. Since the military training is generally completed before the labor market entry, a follow up issue is to what extent drafted individuals are more likely to be employed than nondrafted. Another research question is whether military training is important for individuals with foreign background. Finally, it is important to note that the armed forces today still rely on the conscription system although a standing army is not as remote as it was during the cold war era. The share of the cohort that is drafted today is very small and international peace keeping missions after completed training are relatively common. An interesting question is how military training and experience from international missions are rewarded on the labor market for cohorts that are drafted in later years. 
Table A1: Descriptive statistics

\begin{tabular}{lcccc}
\hline Variable & Mean & Std dev & Min & Max \\
\hline \hline$y_{i}$ & 2,783 & 1,151 & 401 & 45,126 \\
FamInc $_{i}$ & 2,426 & 1,232 & 0 & 23,976 \\
FamEdu $_{i}$ & 2.46 & 1.69 & 0 & 5 \\
Cogn $_{i}$ & 5.31 & 1.84 & 1 & 9 \\
PsAbility $_{i}$ & 5.47 & 1.51 & 1 & 9 \\
Leader $_{i}$ & 5.57 & 1.43 & 1 & 9 \\
Mil $_{i}$ & 0.66 & 0.47 & 0 & 1 \\
HighEduc $_{i}$ & 0.41 & 0.49 & 0 & 1 \\
Experience $_{i}$ & 8.67 & 3.84 & 1 & 15 \\
Married $_{i}$ & 0.21 & 0.40 & 0 & 1 \\
Unempl $_{i}$ & 4.39 & 1.33 & 1.7 & 11.8 \\
& & & & \\
N.obs. $^{\text {Not }}$ & 27,552 & & & \\
\hline
\end{tabular}

Note: 19,107 observations for the Leader variable.

Table A2: OLS results for private category when only including matching variables.

\begin{tabular}{lccc}
\hline Variable & \multicolumn{1}{c}{ All } & Low Educ & High Educ \\
\hline \hline Constant & $7.428 * * *$ & $7.471^{* * *}$ & $7.501 * * *$ \\
FamInc & $0.00004 * * *$ & $0.00005^{* * *}$ & $0.00003 * * *$ \\
FamEdu & $-0.009 * * *$ & $-0.013 * * *$ & $-0.010^{* *}$ \\
PG & $0.030^{* * *}$ & $0.017 * * *$ & $0.030^{* * *}$ \\
PsAbility & $0.033^{* * *}$ & $0.028 * * *$ & $0.043 * * *$ \\
Mil & $0.021 * * *$ & $0.038^{* * *}$ & -0.019 \\
Adj $R^{2}$ & 0.055 & 0.052 & 0.038 \\
F & 34.27 & 24.51 & 6.97 \\
Obs & 18,738 & 13,382 & 5,356
\end{tabular}

Note: $* * *$ one percent significance level, $* *$ five percent significance level, * ten percent significance level. Robust standard errors are used to obtain the t-values. 
Table A3: OLS results for squad leader category when only including matching variables.

\begin{tabular}{lccc}
\hline Variable & \multicolumn{1}{c}{ All } & Low Educ & High Educ \\
\hline \hline Constant & $7.324 * * *$ & $7.441^{* * *}$ & $7.474 * * *$ \\
FamInc & $0.00004 * * *$ & $0.00003 * * *$ & $0.00003 * * *$ \\
FamEdu & $-0.007 *$ & $-0.007 * * *$ & $-0.013 * *$ \\
PG & $0.041^{* * *}$ & $0.022^{* *}$ & $0.029 * * *$ \\
PsAbility & 0.011 & 0.006 & $0.014 * * *$ \\
Leadership & $0.042 * * *$ & $0.037 * *$ & $0.038^{* * *}$ \\
Mil & 0.011 & $0.045^{* *}$ & -0.003 \\
Adj $R^{2}$ & 0.049 & 0.041 & 0.040 \\
F & 10.70 & 2.84 & 5.49 \\
Obs & 6,233 & 2,297 & 3,936 \\
\hline
\end{tabular}

Note: $* * *$ one percent significance level, $* *$ five percent

significance level, * ten percent significance level. Robust

standard errors are used to obtain the t-values. 
Table A4: OLS results for platoon leader category when only including matching variables.

\begin{tabular}{llcc}
\hline Variable & \multicolumn{1}{c}{ All } & Low Educ & High Educ \\
\hline \hline Constant & $7.377^{* * *}$ & $7.039^{* * *}$ & $7.565^{* * *}$ \\
FamInc & $0.00003^{* * *}$ & 0.00003 & $0.00002^{* * *}$ \\
FamEdu & 0.008 & $0.008^{* * *}$ & $0.002^{* *}$ \\
PG & $0.030^{* * *}$ & 0.012 & $0.020^{* *}$ \\
PsAbility & 0.007 & 0.056 & -0.001 \\
Leadership & $0.043^{* * *}$ & 0.033 & $0.044^{* * *}$ \\
Mil & 0.007 & 0.087 & -0.010 \\
Adj $R^{2}$ & 0.050 & 0.104 & 0.042 \\
F & 4.66 & 2.15 & 3.87 \\
Obs & 2,581 & 451 & 2,130 \\
\hline
\end{tabular}

Note: ${ }^{* * *}$ one percent significance level, ${ }^{* *}$ five percent

significance level, * ten percent significance level. Robust

standard errors are used to obtain the t-values. 


\section{References}

Angrist, Joshua D. 1990. "Lifetime Earnings and the Vietnam Era Draft Lottery: Evidence From Social Security Administration Records.” American Economic Review 80(3):313-336.

Angrist, Joshua D. 1998. "Estimating the Labor Market Impact of Voluntary Military Service Using Social Security Data on Military Applicants.” Econometrica 66(2):249-288.

Angrist, Joshua D. and Alan B. Krueger. 2001. "Why Do World War II Veterans Earn More than Nonveterans?" Journal of Labor Economics 12(1):74-97.

Antelius, Jesper and Anders Björklund. 2000. "How Reliable are Register Data for Estimating the Return on Schooling?" An examination of Swedish data. Scandinavian Journal of Educational Research 44(4):341-355.

Berger, Mark C. and Barry T. Hirsch. 1983. "The Civilian Earning Experience of VietnamEra Veterans.” The Journal of Human Resources 18(4):455-479.

Bryant, Richard and Allen Wilhite. 1990. "Military Experience and Training Effects on Civilian Wages.” Applied Economics 22(1):69-81.

Goldberg, Matthew S. and John T. Warner. 1987. "Military Experience, Civilian Experience, and the Earnings of Veterans." The Journal of Human Resources 22(4):62-81.

Heckman, James J. and Richard Robb Jr. 1985 "Alternative Methods for Evaluating the Impact of Interventions: An Overview." Journal of Econometrics 30(1-2):239-267.

Heckman, James J., Hidehiko Ichimura, and Petra Todd. 1998. "Matching as an Econometric Evaluation Estimator.” Review of Economic Studies 65(2):261-294.

Imbens, Guido W. 2004. "Nonparametric Estimation of Average Treatment Effects under Exogeneity: A Review." Review of Economics and Statistics 86(1):4-29. 
Rosen, Sherwin and Paul Taubman. 1982. "Changes in Life Cycle Earnings: What Do Social Security Data Show?" The Journal of Human Resources 17(3):321-338.

Smith, Jeffrey A. and Petra Todd. 2005. "Does Matching Overcome LaLonde's Critique of Nonexperimental Estimators?" Journal of Econometrics 125(1-2):305-353.

The Swedish Act on Liability for Total Defense Services. 